\title{
Cidade de papel e floresta: uma leitura de A represa: romance da Amazônia, de Océlio Medeiros
}

\section{City of paper and forest: a reading of "A represa": romance da Amazônia, by Océlio Medeiros}

Luciana Nascimento ${ }^{*}$

Resumo: Entender as lógicas que estruturam essa diversidade de formas de ocupação urbana na Amazônia torna-se extremamente interessante, pois remete a uma reflexão sobre a formação histórica e cultural dessa região e mais ainda através da literatura, espaço de recriação e captação oblíqua da realidade. Tal reflexão nos permite perceber a interação entre os processos locais e nacionais, ou seja, em que medida essa literatura amazônica expressa a cidade em seus compassos e descompassos com outras narrativas urbanas. Interessa-nos aqui-, mostrar uma leitura do romance A Represa: romance da Amazônia, do escritor acreano Océlio de Medeiros, publicado no Rio de Janeiro, pela Editora Irmãos Pongetti, em 1942.

Palavras-chave: Amazônia. Cidade. Narrativa.

Abstract: Understanding the logic that structures the diversity of urban occupation in the Amazon is extremely interesting since it refers to a reflection on the historical and cultural formation of this region and also to a reflection of literature, which is a space of recreation and capturing of reality. Such reflection allows us to understand the interaction between national and local processes, that is, to what extent the Amazon literature expresses the city, its rhythm and mismatches with other urban narratives. It is relevant to show a reading of the novel A represa: romance da Amazonia, by the writer from the state of Acre Océlio de Medeiros, published in Rio de Janeiro by Irmãos Pongetti publisher in 1942. Keywords: Amazon. City. Narrative.

Em fins do século XIX e início do século XX, ocorreram significativas mudanças na configuração de nossas cidades, sobretudo no Rio de Janeiro e em São Paulo, cidades que acompanhavam o ritmo da modernidade européia,

\footnotetext{
*Doutora em Teoria e História Literária pela UNICAMP. Pós-Doutora em Ciência da literatura pela UFRJ. Docente do Programa de Pós-Graduação em Letras: Linguagem e Identidade da Universidade Federal do Acre. < luciana@ufac.br>.
} 
buscando-se o progresso, a modernidade e a "civilização". O objetivo era fazer o Brasil ingressar no chamado "mundo civilizado", reproduzindo o modus vivendis europeu, com a adoção de novos tipos de lazeres e nova sociabilidade. Neste sentido, as representações literárias em alguns momentos celebram ou reexaminam os melhoramentos urbanos, mostrando a capacidade dos poetas e romancistas em estabelecer uma legibilidade da cidade.

É justamente no século XX que se consagra a cidade como síntese e projeção da modernidade. A cidade passa a expressar, em grande medida, os anseios de uma nova ordem econômica e política com vistas ao progresso. Tal processo pôde ser observado também-, quando se trata da formação do espaço urbano na Amazônia, cujas cidades se formam a partir dos primeiros núcleos de povoamento, na esteira da economia extrativista da borracha, tornando o campo e a floresta, lócus que trazem um significado relativo ao atraso. Assim, se vivencia na Amazônia uma experiência de Belle Époque, como aquela ocorrida em Belém, em Manaus ou em Porto Velho, com a construção da Estrada de Ferro Madeira-Mamoré, cujo evento foi muito apropriadamente chamado por Foot Hardman de "a modernidade na selva", acompanhando o famoso período de fausto do ouro verde.

Se por um lado-, a cidade ascende definitivamente-, por outro, o campo passa por um processo de isolamento e atraso. São vários os aspectos políticos e históricos determinantes desse novo cenário. Todavia, não vamos aqui nos debruçar sobre eles. O que nos interessa é perceber de que maneira essa ascensão da cidade na Amazônia motiva outras escritas de romances, não somente aquelas cuja temática reside numa "poética do verde"-; ou seja, há uma série de obras que Afranio Coutinho (2003) classifica como "romance do ciclo do Norte", cujo autor principal foi Dalcídio Jurandir, sendo que em tais romances são colocados em cena a floresta, seus trabalhadores, a exploração do seringueiro e seus desafios diante da natureza exuberante e hostil a este sujeito. A floresta deixa de ser o espaço idílico postulado pelos viajantes estrangeiros em seus textos nos séculos XVIII e XIX-, para, nos textos ficcionais do século XX (anos 1940 e 1950), se tornar o lugar que se deixa - o lugar do abandono.

Os estudos acerca da literatura de expressão amazônica têm se debruçado sobre as narrativas orais de caráter popular, a narrativa indígena, o caráter social desta ficção, onde expõem a exploração no mundo do trabalho

\footnotetext{
${ }^{1}$ Refiro-me ao livro de Francisco Foot Hardman Trem fantasma: a modernidade na selva (1987).
} 
e a mundivivência no interior da floresta, na qual os homens são encenados como produtos do meio e dotados de um conjunto de regras muito próprias. Entretanto, a representação da cidade na literatura tem sido uma das temáticas menos estudadas, com exceções para alguns estudos, notadamente na área de história, sobre a Belle Époque amazônica em Belém e Manaus.

Acreditamos que as representações da cidade na literatura são importantes, pois a Amazônia precisa ser lida enquanto uma região cada vez mais urbana, com quase $70 \%$ de sua população vivendo nas cidades, ainda que esta estatística possa ser questionada em função das estruturas rural-urbanas ali existentes, tendo em vista que sociedade e território na Amazônia brasileira e de outros países vizinhos, em sua configuração Pan-Amazônica, refletem as intensas mudanças ocorridas nas últimas quatro décadas. As antigas localidades experimentam uma recomposição de seu papel, resultado do confronto social de modelos diversos de apropriação do território e de integração em mercados globalizados.

Entender as lógicas que estruturam essa diversidade de formas de ocupação urbana na Amazônia torna-se extremamente interessante, pois remete a uma reflexão sobre a formação histórica e cultural dessa região e mais ainda através da literatura, espaço de recriação e captação oblíqua da realidade. Tal reflexão nos permite perceber a interação entre os processos locais e nacionais, ou seja, em que medida essa literatura amazônica expressa a cidade em seus compassos e descompassos com outras narrativas urbanas. Interessa-nos aqui, mostrar uma leitura do romance $A$ represa: romance $d a$ Amazônia, do escritor acreano Océlio de Medeiros, publicado no Rio de Janeiro-, pela Editora Irmãos Pongetti, em 1942.

$\mathrm{Na}$ historiografia literária, com exceção da referência a que faz Afrânio Coutinho sobre os romances do ciclo do Norte, há em geral, um vazio nos registros sobre a produção literária de expressão amazônica-, ao longo da história da literatura brasileira, não obstante os esforços dos trabalhos realizados por pesquisadores da UFPA, UFAM, UFAC, UFRR. A falta de registros sobre essa literatura é ainda maior quando se trata da literatura produzida no Acre, o que se explica pelo peculiar e longo processo histórico de sua incorporação ao território brasileiro, que se deu somente nos primeiros anos do século XX (1903). João Carlos de Souza Ribeiro (2007, p.3), assim se expressa: 
A historiografia literária, de cuja escrita emana toda a trajetória da própria literatura, se não excluiu, deixou de incluir o imaginário do povo que surge vigoroso e legendário no seio da floresta. $\mathrm{O}$ rastreamento de símbolos ou de um emblema, que marca esses estrangeiros brasileiros, aos olhos da história e da crítica literárias de base canônica, respectivamente, construiu desde a fundação das escrituras que tematizam a Amazônia, o elo perdido da história da literatura e da literatura artística em análise contínua. Última peça a ser encaixada no complexo quebra-cabeça denominado brasilidade, a Amazônia invisível dá visibilidade ao pluralismo vertente da contemporaneidade, que não se configura na arrolagem consagrada dos textos modelares da literatura dita nacional, e que ainda está à guisa de uma reflexão profunda sobre os veios mais essenciais dessa linguagem no âmbito regional a priori e no espaço universal, a posteriori.

Dos estudiosos que vêm produzindo uma historiografia literária no Acre, destacamos as professoras Olinda Assmar, Laélia Rodrigues, Margarete Prado Lopes, Simone Souza Lima, todas da UFAC. Laélia Rodrigues Silva em Acre-Prosa \& Poesia 1900-1990 (desdobramento da pesquisa empreendida no seu doutorado, sendo uma pesquisa contínua na sua vida acadêmica, agora na qualidade de professora visitante), nos afirma que grande parte das produções literárias escritas na Amazônia-, projeta-se a partir de uma tentativa de descortinar uma questão identitária, associada à temática do isolamento e da relação com seu espaço:

Com estigmas de deserto e de inferno verde e com uma trajetória histórica acentuadamente marcada pela exploração de recursos naturais, a cultura amazônica tem sido determinada por dois elementos significativos: o isolamento e a busca da identidade. (SILVA 1998, p. 17).

Utilizando a metáfora de Leandro Tocantins, que dá título à sua obra O rio comanda a vida, percebe-se na obra de Océlio Medeiros, A represa: romance da Amazônia, que o próprio título aponta para o espaço aquático, utilizando a imagem da represa, ou seja, sendo represadas as vidas das pessoas que aí vivem: "Um rio preguiçoso, recebendo em frente da cidade o tributo escasso de um afluente, ia minguando angustiosamente as suas águas barrentas, por entre as escarpas dos barrancos espetados de canaranas ${ }^{2}$ esguias." Nesta passagem, o fio da água de um rio estreito aparece para caracterizar a imagem da decadência pela qual passa a cidade

\footnotetext{
${ }^{2}$ Capim de Angola.
} 
de Xapuri, com a baixa na economia da borracha, em cujas primeiras cenas, o narrador expõe os fatos cotidianos e prosaicos dos habitantes da cidade e a falência dos seringais.

Em outra imagem do romance de Medeiros, a água mostra sua força, a partir da cheia do rio Acre, que destrói o Seringal Iracema, do Coronel Belarmino:

O rio parecia um mar. As chuvas da noite ainda o alargaram mais. As barracas restantes tinham sido arrastadas. As hortas, os roçados, os campos estavam inundados [...] Também passou de bubuia um tronco de sumaúma, que a ventania forte da madrugada, sacudindo o corpo da mata, havia desenterrado.

É nesse cenário de alagação, em que a água tudo encobre, que o dilúvio nos aponta para uma metáfora da restauração e da mudança do ciclo da vida. E no romance de Océlio de Medeiros é exatamente após a alagação do Seringal Iracema, que ocorre o deslocamento de seus habitantes em direção à cidade de Rio Branco.

Dividida em 16 capítulos, a obra A represa: romance da Amazônia inicia-se em Xapuri, cuja decadência da borracha leva à falência geral da cidade. O personagem Antonico, habitante de Xapuri, vai morar no Seringal Iracema, de propriedade do Coronel Belarmino, que por sua vez, o envia a Belém para estudar. A narrativa abrange aproximadamente 30 anos da vida do Acre, compreendendo o período de decadência do primeiro ciclo da borracha, com o deslocamento do seringal para a cidade, chegando aos primeiros anos da II Guerra Mundial, época conhecida como "Batalha da Borracha", o que dá origem a uma nova fase na vida dos personagens, ou seja, é a volta para o seringal, na esperança de ganhos com a economia gomífera, dando-se fim à narrativa. Ou seja, a narrativa se dá entre as duas grandes guerras, que marcaram a ascensão e decadência dos dois ciclos da borracha.

Laélia Rodrigues Silva ressalta que o tempo se constrói a partir de idas e vindas dos habitantes do território, do seringal para a cidade e vice-versa, cujo tempo histórico é motivado por duas grandes guerras internas, que são motivadas por interesses externos: a Revolução Acreana e a Batalha da Borracha. Justamente esse deslocamento para a cidade e a vida social e cotidiana desses personagens na cidade que nos interessam mais de perto,

${ }^{3}$ Samaúma. Árvore típica da paisagem amazônica. No falar acreano é sumaúma. 
pelo fato de nossas pesquisas terem como foco a representação da cidade na literatura, a legibilidade urbana e o tópico literatura e experiência urbana, a partir da leitura que os literatos fazem da cidade, como espaço afirmativo do moderno, mas também como lócus do embaralhamento das existências e espaço das novas oportunidades e mudança de vida. Medeiros (1942, p, 107) assim descreve a chegada dos antigos moradores do Seringal Iracema, na cidade de Rio Branco:

Já na boquinha da noite, a cidade de Rio Branco começou a se despir, como uma visão salvadora, aos olhos dos retirantes, mostrando seus arrabaldes venezianos, a cadeia velhas, onde funciona o hospício, a cruz da matriz, caída para um lado e as torres de luz elétrica, de uma banda e doutra.

Destaque-se que a visão primeira dos personagens sobre a cidade é de um espaço moderno, portanto, na narrativa de Medeiros temos o distanciamento do espaço Amazônico unicamente construído por florestas. De acordo com Carlos Gonçalves (2001, p.16) “a Amazônia muitas vezes é vista como sendo a última fronteira, onde parece existir uma natureza intocada." Entretanto, essa visão acerca da Amazônia, na verdade, constitui uma construção imagética que se deu ao longo da história, cujas origens podemos situar no discurso dos viajantes estrangeiros maravilhados diante de uma natureza exuberante, o que acabou por fundar uma extensa linha de tradição: "A imagem mais comum do que seja a Amazônia é a de que se trata de uma imensa extensão de terra, onde o principal elemento de identificação é uma natureza pujante, praticamente indomável que a história nos legou, intocada" (GONÇALVES, 2001, p. 20).

Em contraposição a essa imagem e lendo a Amazônia em sua urbanização nascente, Océlio de Medeiros, na narrativa de A represa, nos mostra a composição do espaço urbano de Rio Branco nos primeiros anos de sua formação, momento em que se consolida a sociedade local e se estabelecem os primeiros elos entre os moradores: " Rio Branco, em terras do antigo Seringal Empresa, fundado por Niotel Maia, é uma cidade nova. Ainda está

\footnotetext{
${ }^{4}$ O nome do fundador do Seringal Empresa é Neutel Maia, mas no livro de Océlio Medeiros encontra-se grafado Niotel Maia, o que talvez se explique pela sua intenção explícita na introdução do livro: "O autor que compreende o romance como uma arte de focalizar a vida em movimento, faz questão de lembrar aqui a legenda que hoje trazem os filmes de Far West americano, para ressaltar que estas
} 
na primeira infância do urbanismo. Talvez não tenha uns trinta ou quarenta anos de existência organizada."

Para caracterizar a ideia de cidade na Amazônia, o escritor acreano, como em muitas passagens de sua obra, recorre à imagem do rio, conformando tal imagem às cidades e às pessoas que vivem na região:

As cidades amazônicas são obra de decadência. Os rios humanos, nos primeiros tempos da borracha, saindo do Nordeste, formam correndo Amazônia adentro, divididos em centenas de braços. Risos malucos, sem rumo certo, que vieram do Atlântico, em sentido contrário aos rios de água, como que para desaguar no Pacífico, cavando na sua corrida pela mata, o próprio leito. O que foi mais longe, rio pororocante de cearenses brabos, chegou até o Território do Acre, nos domínios da Bolívia e do Peru. Só não foi mais longe porque esbarrava nas muralha dos Andes. (MEDEIROS, 1942, p. 108)

A cidade como espaço de embaralhamento das existência humanas é encenada por Océlio Medeiros associada à imagem do rio, que mais do que um elemento da paisagem geográfica, torna-se uma imagem da diversidade de pessoas que passam a compor a cidade:

Rio Branco, com seu igapó de homens, numa região onde ninguém nunca pensou em edificar uma cidade, é por isto um rio que perdeu o seu destino. Dá a ideia de uma represa. Uma enorme represa humana, onde se agitam num drama de isolamento, os recalques e as paixões. Trabalhado pelas piores remanescências, o grosso da sociedade sofre na sua contenção, buscando uma saída, buscando um fim que nunca chega.” (MEDEIROS, 1942, p. 109)

O período em que Océlio Medeiros tematiza a cidade coincide com uma fase da urbanização de Rio Branco em que temos a imagem da "cidade partida", ou seja, foi a época em que o eixo urbano se desloca do que hoje chamamos de segundo distrito para a margem esquerda do rio Acre, a partir da construção do Palácio do Governo, sede da administração do Departamento do Alto Acre:

páginas não constituem alusão a quem quer que seja. A sua técnica (...) consistiu em buscar personagens de ficção, ou mesmo inspiradas nos modelos reais, para cenas que colheu numa apreensão caricatural, como matéria-prima do romance, no sofrimento da vida amazônica." 
Rio Branco fica dividida ao meio pelo Acre. No lado esquerdo estão o Palácio do Governo, a Matriz, o Forum, a Polícia, o Obelisco e o busto de João Pessoa. Aí moram as principais famílias. Esse lado lembra o menino do colégio de padre, cheio de bons costumes, religioso e moralista.

No lado direito, em verdadeira contradição, estão as lojas dos sírios gananciosos ocupando quase toda a rua da frente, com fazenda de amostra nas fachadas de madeira das casas baixas, o Pavilhão, as pensões, as casas de jogo, o beco do meretrício, o Hotel Madri e o poeta Juvêncio. ${ }^{5}$ Faz lembrar, nos contrastes da terra, o menino perdido, o menino de rua. (MEDEIROS, 1942, p. 109).

Essa bipartição da cidade em espaço oficial, da administração e das famílias importantes em contraposição ao primeiro núcleo de povoação, onde se exibiam os avessos da cidade, ou seja, o meretrício, a casa de jogo e a boêmia demarcam a cidade como espaço da exclusão e de um possível ordenamento urbano, que vinha na esteira do urbanismo moderno utilizado em muitas cidades brasileiras.

No tocante à vida social e ao lazer na cidade, Medeiros nos mostra que no lado esquerdo a sociabilidade está centrada nas festas de família, enquanto do lado direito reina a diversão, a vida boêmia, a sensualidade, registrando a presença do poeta Juvenal, que ele grafa como "Juvêncio". Vale ressaltar que Juvenal Antunes foi o poeta boêmio da cidade de Rio Branco, que vivera no Hotel Madri, era boêmio, dado às bebedeiras, marcando presença constante no bar do hotel, cujos versos mais famosos foram "O elogio à preguiça", no qual o poeta potiguar exalta o ócio como fonte de criatividade e as mais variadas versões para os versos dedicados à Laura, personagem recorrente na lírica de Juvenal.

Uma luz mortiça vela o sono tranqüilo de Rio Branco. No lado esquerdo, quando não há uma festinha ou não faz luar, as famílias se retiram antes das nove horas. No lado direito, ao contrário, a insônia vai pela madrugada, com as danças no Bodovaldo e as bagunças na pensão da nega Deltrudes, com as jogatinas, as bebedeiras, as farras e as brigas por questões de ciúme.

$[\ldots]$

\footnotetext{
${ }^{5}$ Referência ao poeta potiguar Juvenal Antunes, que morava no Hotel Madri e exercia a função de promotor de Justiça em Rio Branco, na década de 1920.
} 
No beco de permanente cheiro de amoníaco, as mulheres agarram os transeuntes para as extravagâncias de amor. No Madri, com um largo salão de bilhares, há quem trate de negócios, comissões e consignações, os turcos procurando enganar-se mutuamente. (...) $\mathrm{E}$ numa banca reservada, o poeta Juvêncio debocha a humanidade e repete seus versos à Laura:

'- A tua boca, ò Laura, tem o sabor das uvas

E o gosto d'água das primeiras chuvas!....'

E, ao chegar à última rima, arreia a palma da mão sobre a tábua da banca, chamando os nomes mais feios e contando os casos mais escabrosos." (MEDEIROS, 1942, p. 111-112)

Océlio Medeiros nos mostra os aspectos mais típicos de uma cidade em um nascente processo de urbanização, cuja vida social estava restrita às poucas reuniões e aos poucos espaços de sociabilidade, cujo descompasso com o moderno é assim descrito pelo escritor acreano:

O Cine Rio Branco, do lado esquerdo, o único cinema da cidade, enche $\mathrm{o}$ ar de sons antigos, tocando na sua poderosa vitrola as músicas que já saíram de moda no mais distante bairro do Rio de Janeiro.

A luz já vai alta. Uma lua que também existe na barriga dos bêbados. A gente ouve a cantiga saudosa de dois meninos brincando:

- Ciranda, cirandinha!

Vamos todos cirandar!

Passa, passa bom barqueiro

Passa, passa devagar,

Passa, passa todo mundo

Mas alguém há de ficar...

(MEDEIROS, 1942, p. 112)

Lançando o seu olhar sobre a cidade em transformação, Medeiros recupera a memória de um tempo de inocência ao atravessar na cena urbana a cantiga da infância com o avesso da cidade e a boêmia, contrapondo com os versos de Juvenal à chamada "literatura sorriso da sociedade", misturando-se, ainda, uma profusão de sons que atravessam a paisagem. 
Além da vida social, Océlio de Medeiros registra a presença do jornal "O Acre", como meio de comunicação para aquela sociedade nascente,cujo território havia sido incorporado ao Brasil há apenas 40 anos. O jornal, conforme postula Benedict Anderson (2008), cumpre o papel de unificar a nação, a comunidade imaginada, cuja missão de estabelecer uma idéia de homogeneidade e de pertencimento àquela nação. Océlio Medeiros em A represa, ironicamente mostra o jornalista Amadeu Aguiar, que intitulava o jornal - O Acre - como "o maior órgão de circulação em todo o Brasil":

Amadeu como jornalista, tinha padronizado os adjetivos para as personagens destacadas de Rio Branco: o Prefeito era dinâmico, o Dr. Romualdo era a o jovem esculápio, o maçon Marcos era o venerando, o desembargador era o egrégio, o comandante da polícia era o m. d. Comandante da P.M.T.A, o professor Cazuza era o provecto, o Dr. Fabricio era o causídico, o Mario era o gentil poeta, o Anselmo era o emérito, o Juvêncio era o decano dos nossos homens de letras [...] Aos viajantes que chegavam de navio ou de avião, tinha a frase: chegou ontem a esta cidade por via-líquida ou então aportou à nossa capital por via-gasosa..."

Note-se o tom crítico e cortante do narrador ao colocar em cena o jornalista que afirmava ser o seu jornal "o maior órgão de circulação do Brasil", mas que na verdade se mostrava ser um veículo comprometido em tecer elogios aos poderosos e uma caricatura distorcida das colunas sociais dos jornais das grandes cidades, pelo uso de expressões "via líquida", "via gasosa", ou seja, o vício da utilização de um discurso empolado.

O espaço da cidade é, sobretudo, um espaço de transitoriedade para os retirantes, antigos habitantes do seringal Iracema, de propriedade do Coronel Belarmino e também para o próprio Coronel. E é em meio ao anúncio do início da Segunda Guerra Mundial veiculado pelo Jornal O Acre, que os retirantes e o coronel organizam a volta para o Seringal Iracema.

Recrudesce a guerra no front! Novos contingentes ingleses! As praças de Manaus e Belém informam as últimas cotações da borracha! O preço subiu o dobro em apenas dois meses

[...] Rio Branco endoideceu. Todo mundo quer voltar para a seringa. Os soldados da Polícia Militar procuraram o Coronel Donato Para pedir baixa. Ir para os seringais dava mais dinheiro do que ser soldado." (MEDEIROS, 1942, p. 185-190). 
Esse período, chamado de Batalha da Borracha, no qual homens foram recrutados no Nordeste, para o trabalho nos seringais, sendo que estes, encontravam-se naquela altura despovoados, deram origem aos chamados "soldados da borracha". Assim, inicia-se uma segunda corrida pelo ouro verde e se dá a travessia de volta para o seringal, sendo que nesse momento as personagens nutrem grandes esperanças de riqueza e de recuperação de sua identidade. Esse retorno é marcado por Océlio de Medeiros (1942, p. 209-210), nas últimas linhas de sua narrativa, evocando novamente a imagem da represa:

Os retirantes, como as águas, saíam pelos sangradouros, para voltar certamente um dia, na hora futura do desânimo, como num círculo vicioso. Uma onda verde, de limo e de lodo, continuaria a ser alma da superfície da cidade, em cujas profundezas dormiam as glórias de um passado de lutas. As águas de um inverno próximo, trazendo a força renovadora de uma geração, virão nos rios das futuras emigrações. Até aí, entretanto, a represa haverá de ficar, acrescida de mais uma gota de sofrimento, no seu marasmo e no seu cenário, com os homens, as paixões e os sentimentos estagnados, numa paisagem de sacrifício e de renúncia.

A guisa de conclusão, podemos afirmar que $A$ represa: romance da Amazônia não se constitui como obra de denúncia das questões sociais ou das condições de trabalho nos seringais, mas tematiza a Amazônia na sua outra face, ou seja, na constituição do seu espaço urbano, que no caso acreano se deu pela bipartição da cidade, que para além de uma fronteira geográfica definiu também uma fronteira social. Como bem afirma Kublai Khan, narrador de As cidades invisiveis, de Italo Calvino (1990, p. 14-15), as cidades não são feitas apenas de um projeto, mas de sentimentos, ressentimentos, tradições e acontecimentos, desde os mais monumentais aos mais prosaicos. Afinal, o passado da cidade está escrito: "Na linha da mão, escrito nos ângulos das ruas, nas grades das janelas, nos corrimãos das escadas, nas antenas dos para-raios, nos mastros das bandeiras, cada segmento riscado por arranhões, serradelas, entalhos, esfoladuras..."

\section{Referências}

ANDERSON, Benedict. Comunidades imaginada: reflexões sobre a origem e a difusão do nacionalismo. Trad. Denise Bottmann. São Paulo: Companhia das Letras, 2008. 
CALVINO, Italo. As cidades invisíveis. Trad. Diogo Mainardi. São Paulo; Companhia das Letras, 1990.

COUTINHO, Afrânio. A literatura no Brasil. 6. ed. São Paulo: Global, 2003. v.4

GONÇALVES, Carlos Walter Porto. Amazônia, amazônias. São Paulo: Contexto, 2001.

MEDEIROS, Océlio. A represa: romance da Amazônia. Rio de Janeiro: Irmãos Pongetti, 1942.

RIBEIRO, João Carlos de Souza. A poética do verde. Ramal de Ideias. Revista de Conhecimento. Rio Branco; EDUFAC, 2007. Disponível em: < <ttp://www.ufac.br/portal/ orgaos-complementaress/edufac/revistas-eletronicas/revista-ramaldeideias/edicoes/edicao-1/ caminho-das-letras/a-poetica-do-verde>. Acesso em: 18 agosto 2011.

SILVA, Laélia Rodrigues. Acre: prosa \& poesia, 1900-1990. Rio Branco: EDUFAC, 1998.

TOCANTINS, Leandro. O rio comanda a vida: uma interpretação da Amazônia. 9. ed. Manaus: Valer, 2000.

Recebido para publicação em 20 nov. 2011. Aceito para publicação em 15 dez. 2011. 